\title{
"Prof.,porque a Maria não tem pipi? Ela perdeu o pipi??": narrativas de crianças, famílias e professoras, referentes a sexualidade infantil
}

\begin{abstract}
Resumo: O presente texto objetiva apresentar resultados de uma pesquisa que teve a intenção de contemplar no cotidiano da prática pedagógica um olhar atento sobre a sexualidade infantil, especificamente como as relações corpóreas/afetivas são abordadas no contexto educativo, através de análises das observações realizadas durante $\mathrm{o}$ ano de 2015, com um grupo de crianças de 2 a 4 anos de idade, em um Centro de Educação Infantil do município de Imbituba/SC. Buscou-se compreender as pistas que essas crianças pequenas dão em relação aos seus corpos e as interações entre elas, bem como as narrativas das professoras e famílias que convivem com elas, na tentativa de entender as relações entre os pares e os sentidos dos adultos frente as expressões infantis. Para isso, são utilizados registros de diários de campo das situações e narrativas ocorridas no cotidiano das crianças, familiares e profissionais da instituição. Analisando as narrativas dos/as envolvidos/as na pesquisa, pode-se perceber, mesmo implicitamente, que a sexualidade está presente no cotidiano das famílias, profissionais e crianças, pois é frequentemente abordada por eles/as a partir de uma lógica heteronormativa. Assim, neste trabalho, a intenção não foi trazer respostas prescritivas relacionadas à sexualidade infantil, mas sim, refletir sobre as práticas e concepções corpóreas afetivas estabelecidas pelas crianças.
\end{abstract}

Palavras-chave: Educação Infantil. Sexualidade infantil. Criança. Prática pedagógica.

\section{"Teacher, why Maria has not pipi? She lost pipi ": children stories, families and teachers, related to infantile sexuality.}

Abstract: This paper aims to present results of a study intended to look at the everyday pedagogical practice a watchful eye on child sexuality, specifically as corporeal / emotional relationships are addressed in an educational context through analysis of observations made during 2015, with a group of children aged 2 to 4 years old, in a children's Educational Center in the city of Imbituba / SC. We sought to understand the clues that these little children give in relation to their bodies and their interactions, and the narratives of the teachers and families living with them in an attempt to understand the relationship between the couple and the senses of adults ahead the children's expressions. For this, they are used daily records of field situations and narratives occurred in the daily lives of children, families and professionals of the institution. Analyzing the narratives of / the involved / the research, it can be noticed, even by implication, that sexuality is present in the daily lives of families, professionals and children, as is often approached by them / as from a heteronormative logic. In this work, the intention was not to bring prescriptive answers related to infantile sexuality, but to reflect on the practical and affective bodily conceptions established by children.

Keywords: Research with Children; Childhood and Gender; Childhood Education; Peer Culture.

\footnotetext{
'Graduada em Pedagogia pela Universidade do Sul de Santa Catarina. Resultado da pesquisa realizada para obtenção do título de especialista em docência na Educação Infantil (CEDEI/NDI/UFSC). E-mail: sabrinafilipini@gmail.com 2Doutora em Psicologia (PPGP/UFSC). Professora Orientadora do Curso de Especialização em Docência na Educação Infantil (CEDEI/NDI/UFSC) e do Núcleo de Desenvolvimento Infantil (NDI). E-mail:reginaingrid@gmail.com
} 


\section{Iniciando o diálogo}

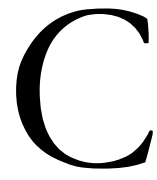

omo professora na educação infantil da rede pública municipal há dois anos, vejo a necessidade de contemplar no cotidiano da prática pedagógica um olhar atento sobre a sexualidade infantil, pois é perceptível a curiosidade que as crianças têm sobre seus corpos, bem como as relações que envolvem o prazer e as mudanças corpóreas/afetivas, que por vezes são tratadas por muitas/os professoras/es como um tema sem importância ou até mesmo inadequado à idade dos/as pequenos/as.

Conforme a Lei de Diretrizes e Bases da Educação Nacional (Lei 9.394/96), em seu artigo 29, “A educação infantil, primeira etapa da educação básica, tem como finalidade o desenvolvimento integral da criança de até 5 (cinco) anos, em seus aspectos físico, psicológico, intelectual e social, complementando a ação da família e da comunidade.". Desta forma, é imprescindível trataras dimensões que envolvem a sexualidade ${ }^{3}$ como parte integrante do sujeito humano, pois:

A sexualidade é um aspecto central do ser humano ao longo da sua vida e engloba sexo, identidade e papel de gênero, orientação sexual, erotismo, prazer, intimidade e reprodução. A sexualidade é vivida e expressada em pensamentos, fantasias, desejos, crenças, atitudes, valores, comportamentos, praticas, papéis e relacionamento. A sexualidade pode envolver todas essas dimensões, mas nem sempre todas são vivenciadas ou expressas. A sexualidade é influenciada por uma interação de fatores ordem biológica, psicológica, social, econômica, política, cultural, ética, legal, histórica, religiosa e espiritual. (GÊNERO,DIVERSIDADE E EDUCAÇÃO, 2009, p.121)

E como pensar a sexualidade infantil? Como compreender e refletir sobre suas especificidades? Parece-me que estar atento a sexualidade desde a primeira infância é direito da criança e nosso dever enquanto docente, já que uma das funções dos espaços de educação infantil reside na complementariedade da educação familiar. Mas como pensar tal complementação se para muitos familiares a sexualidade infantil é um tabu?

\footnotetext{
3 Sexualidade - dimensão humana constituída pelas relações de afeto, toque e prazer com seu corpo e o corpo do outro. Ver mais em Gênero e Diversidade na Escola: Formação de professoras/es em gênero, sexualidade, orientação sexual e relações étnicoraciais (2009).
} 
Algumas pesquisas, como as da autora Guacira Lopes Louro (2000) e do autor Marcos Lopes de Souza (2015), apontam que a sexualidade quando abordada no contexto educativo, está na grande maioria das vezes atravessada por visões e idealizações prontas e concebidas por uma sociedade heteronormativa, restringindo a ideia de que a sexualidade seja discutida nas instituições educativas e quando discutidas, são a partir, apenas, da concepção biológica e preventiva. Percebo, no cotidiano, que muitas das vezes os/as profissionais da educação infantil temem esbarrar em conceitos já concebidos pela família. Falar sobre sexualidade não parece ser a tarefa mais difícil, pois diz respeito a uma dimensão da nossa condição humana, o que me parece um desafio é o leque de interrogações que se abrirá com as crianças, familiares e também no interior das próprias instituições educativas.

Falar sobre gênero e sexualidade na escola tem se constituído como um lugar de tensão, incertezas e intranquilidades, especialmente, pelo receio da equipe escolar em relação ao posicionamento das famílias sobre o ensino dessa temática (SOUZA, 2015, p. 05).

Mas se as instituições de educação infantil não estiverem atentas e abertas a essas questões para que possam discutir sobre a sexualidade em suas concepções biológica, histórica e cultural, de quem a família espera esse debate? Conforme Meira e Santana (2014, p. 164):

[...] o trabalho desenvolvido no âmbito escolar deve ser um processo formal, planejado e sistematizado devendo este também abordar as diferentes visões, crenças, valores e conhecimentos que são transmitidas pela família, mídia e sociedade. Nesse contexto, é responsabilidade da escola oferecer ao educando informações além daquelas que ele já possui e esclarecer as dúvidas ou distorções existentes, propiciando uma reflexão do aluno perante aquilo que lhe foi exposto, favorecendo um pensamento crítico e o surgimento de uma opinião a respeito dos assuntos abordados.

A sexualidade, por se tratar de uma dimensão humana presente nas relações, pode ser pensada e intencionalmente mediada pelas/os professoras/es com as crianças pequenas no cotidiano da prática pedagógica na educação infantil. Digo intencionalmente mediada, dada às demandas cotidianas, presentes na relação corpóreas, que as crianças estabelecem entre si, e que podem ser pensadas e planejadas para que a sexualidade não seja "[...] destituída de seus significados maiores e dos sentidos dos valores que a investem, desvirtuando suas dimensões positivas, saudáveis e prazerosas na vida humana" (TUCKMANTEL, 2011, p. 11).

As dimensões que envolvem corpo e sexualidade são consideradas temáticas da Educação Sexual, ainda que causem muitas discussões e controvérsias. Essas, por sua vez,foram inicialmente abordadas pelos Parâmetros Curriculares Nacionais ( $\mathrm{PCNs}$ ), pois aparece pela primeira vez nas orientações curriculares como um dos Temas Transversais, "estes temas retratam um conjunto de eixos condutores das atividades escolares que, não estando ligados a nenhuma disciplina específica, seriam comuns a todas" (TUCKMANTEL, 2011, p.45). Conforme os PCNs, a Educação Sexual deve ser abordada de forma articulada juntamente com outros temas, tais como: saúde, ética, meio ambiente e pluralidade cultural. 
A discussão sobre sexualidade no espaço educacional, mesmo que incipiente, encontra amparo legal na Proposta Curricular do Estado (2014), em que incita uma educação para a diversidade sexual, para as relações de gênero e também para que a sexualidade seja apresentada como um conceito que ultrapasse a caracterização simplesmente biológica, sendo entendida em suas diferentes concepções, como uma identidade construída na cultura e no meio social.

É importante mencionar que as Diretrizes Curriculares Nacionais (DCN/2010) são normas obrigatórias para a educação básica que orientam o planejamento curricular das instituições educacionais e sistemas de ensino, implantadas pelo Conselho Nacional de Educação (CNE). Guizzo e Felipe (2015, p. 07), discorrem corretamente sobre as DCNs:

As Diretrizes recomendam a inserção da discussão das diferenças sociais, culturais, raciais, sexuais e de gênero, já que o ingresso de diferentes sujeitos oriundos de distintos grupos sociais, étnicos, raciais e sexuais vem causando não só grande impacto nas instituições escolares, como também nos profissionais que nelas atuam.

Sendo a educação infantil uma etapa da educação básica, torna-se obrigatório e imprescindível ao planejamento das instituições de educação infantil, dar espaço e importância para a sexualidade desde a primeira infância.

Além da revisão dos documentos legais, procurei em bibliotecas virtuais como a Scientific Electronic Library Online (SCIELO) e a Associação Nacional de Pós-Graduação e Pesquisa em Educação(ANPED), também nas bibliotecas da Universidade de São Paulo (USP) e na Universidade Federal de Santa Catarina (UFSC), publicações dos últimos 10 anos ${ }^{4}$ que contribuíssem com essa pesquisa.Encontrei vinte e três artigos que auxiliaram minhas análises. Destes vinte e três artigos, selecionei os/as autores/as que discutiam a sexualidade infantil como uma real necessidade a ser trabalhada em todas as suas dimensões, tanto biologicista, modo como geralmente é tratada na maioria das instituições educativas, como também pelas perspectivas culturais e históricas (PARREIRA e SILVA, 2015).

Tuckmantel (2011), Costa (2012), Meira e Santana (2014), Guizzo e Felipe, Parreira e Silva e Souza (2015) discutem a importância da qualificação na formação docente sobre a sexualidade e as "polêmicas e conflitos entre docentes e pais de alunos quando trabalhada em sala de aula" (MEIRA e SANTANA, 2014, p. 2).

Salgado, Mariano e Oliveira (2015) discutem como a sexualidade infantil é concebida pelos adultos. Conforme os/as autores/as, espera-se sempre pela inocência e ingenuidade infantil. Ideia esta que é criticada por eles/as, como vemos na citação a seguir:

[...] a produção de conhecimento sobre a infância não se dá no tratamento metodológico de tomar a criança como um sujeito isolado, arrancado de seu contexto, mas como ator social que, no próprio processo de pesquisa, traz os sentidos de viver a

${ }^{4}$ Utilizo trabalhos anteriores, porém meu foco foi para as pesquisas da última década. 
infância em uma temporalidade e cultura bem específicas. (SALGADO, MARIANO e OLIVEIRA, 2015, p. 3).

A autora Silvia M. A. Zorning (2008), por sua vez, faz uma análise da relação que os adultos estabelecem com as especificidades das crianças, principalmente das crianças pequenas, uma infância considerada pura, livre de qualquer forma de sexualidade, em que elas, para agradar as nossas expectativas enquanto adultos, são, muitas vezes, privadas de conhecer melhor seus corpos. Para Carvalho (2015), a inocência que é destinada à criança é dada por nós, pois se uma criança se expressa corporalmente de modo que nós adultos entendemos como sendo algo exclusivo do universo adulto, não é mais vista como um ser inocente. Desta forma, segundo a autora, muitas vezes a criança aparenta certa ingenuidade para alçar da liberdade, que, de outra forma, não a teria. E analisa que a separação entre os universos infantil e adulto nada mais é que uma construção histórica, conforme explicitado pelos/as autores/as a seguir: "Nas cenas do processo histórico de constituição do conceito de infância na cultura ocidental, a sexualidade precisa ser expurgada da vida das crianças para a solidificação do desenho da infância inocente" (SALGADO, MARIANO e OLIVEIRA, 2015, p. 02).

Já autoras/es como César (2009), Asinelli-Luz e Dinis (2007) discutem sobre a Educação Sexual, porém sobre o aspecto da prevenção às doenças sexualmente transmissíveis (DST’s) e a gravidez na adolescência, ou seja, a sexualidade atrelada ao ato sexual e as mudanças biológicas, a partir da lógica da escolarização e disciplinarização dos corpos. Desde cedo e principalmente nos espaços educativos, as crianças aprendem a se comportar a partir de uma lógica normatizadora dos corpos, por isso essas discussões fazem sentido na Educação Infantil. Nesse ínterim, meninas devem se portar de maneira delicada, sentar-se com as pernas fechadas, por exemplo, para dentro dessa lógica não despertar a curiosidade dos meninos. Desta forma, busca-se ainda em crianças, projetos de adultos civilizados. Ou ainda, crianças que não expressem aspectos relacionados à sexualidade, pois fica indiretamente suposto que a sexualidade é um assunto que tem idade "certa" para ser discutida.

E ainda, conforme Nogueira (2015), sobre as identidades de gênero, quando não correspondem ao considerado "normal" (masculino/menino e feminino/menina) ferem a sexualidade, a heteronormatividade 5 , ou seja, marginalizam as orientações sexuais não heterossexuais, sendo essas silenciadas no cotidiano da Educação Infantil.

Essa breve revisão das pesquisas foi importante para situar a produção da área. A partir desse levantamento bibliográfico, realizo a análise crítica da prática pedagógica. Desse modo, trago algumas análises das observações realizadas por mim, durante o ano de 2015, com meu grupo de crianças de 2 a 4 anos de idade.

${ }^{5}$ Heteronormatividade: "Termo que se refere aos ditados sociais que limitam os desejos sexuais, as condutas e as identificações de gênero que são admitidos como normais ou aceitáveis àqueles ajustados ao par binário masculino/feminino. Desse modo, toda a variação ou todo o desvio do modelo heterossexual complementar macho/fêmea - ora através de manifestações atribuídas à homossexualidade, ora à transgeneridade - é marginalizada/o e perseguida/o como perigosa/o para a ordem social". Ver mais em Gênero e Diversidade na Escola: Formação de professoras/es em gênero, sexualidade, orientação sexual e relações étnico-raciais. (2009, p. 128). 
O objetivo geral deste trabalho foi analisar como essas crianças pequenas aprendem a lidar com questões sobre sexualidade, tendo em vista que elas, neste período, estão descobrindo e conhecendo formas de sentir prazer, e formando suas opiniões e conceitos referentes ao assunto. E, como objetivo específico, compreender como se dão as interações entre crianças pequenas com relação à sexualidade infantil e como as professoras e familiares, que convivem com elas, agem em relação a este assunto.Além disso, descrevo as situações ocorridas no dia a dia das crianças através dos registros escritos,com a intenção de pensar/refletir sobre as pistas que elas nos dão em relação aos seus corpos e as possíveis curiosidades delas referentes ao sexo oposto e a posição familiar diante do exposto.

Apresento a seguir a contextualização do campo e dos sujeitos da pesquisa, seguido pelas análises, que estão divididas por seções compostas pelas narrativas de familiares, professoras e crianças. Trago, por fim, as considerações acerca da pesquisa.

\section{Contextualização do campo e dos sujeitos da pesquisa}

O Centro Municipal de Educação Infantil (CMEI) em que trabalho foi inaugurado no ano de 2010 e fica localizado em um bairro de área rural do Município de Imbituba/SC, que atende ao total de quinze Centros Municipais de Educação Infantil. Desde a sua inauguração não há um Projeto Político Pedagógico (PPP).

A instituição é uma casa pequena e "adaptada" com duas salas e um refeitório que eram os antigos quartos da casa, uma sala onde fica a coordenação, uma cozinha e apenas um banheiro de uso geral, para crianças e funcionárias/os. Não há biblioteca, brinquedoteca e área coberta na parte externa. Esta, por vez, tem um gramado e um parque que está interditado por apresentar rachaduras nas madeiras que suportam a casinha e os balanços. Mas, as salas são bem abastecidas de brinquedos e livros, o que não limita o desenvolvimento das crianças pela falta desses materiais.

O Município trabalha com o sistema Aprende Brasil da editora Positivo ${ }^{6}$, o qual fornece o material didático ${ }^{7 a ̀ s ~ e s c o l a s ~ e ~ t a m b e ́ m ~ a o s ~ C e n t r o s ~ d e ~ E d u c a c ̧ a ̃ o ~ I n f a n t i l . ~ O u ~ s e j a, ~ a s ~ i n s t i t u i c ̧ o ̃ e s ~ r e c e b e m, ~}$ todo início de ano, os cadernos de atividades ${ }^{8}$, trocados por semestre ou bimestre dependendo da faixa etária do grupo destinado. Para o meu grupo são apenas dois cadernos semestrais. Vale ressaltar que temos alguns "cursos" oferecidos pela editora, nos quais são apresentados aos/às professores/as da rede o material didático a ser utilizado no início do ano letivo.

Trabalho com crianças do Grupo 3 - G3, que corresponde à faixa etária de 2 a 4 anos.O grupo é composto por doze crianças, sendo cinco meninas e sete meninos. O outro grupo é o G4, com crianças de

\footnotetext{
6 O município trabalha com esta editora desde o ano de 2013.

7 O caderno de atividades é utilizado semanalmente, ele é divido por eixos, suas atividades são bem diversificadas, possui leitura de imagens, desenhos, comparações, noções de quantidade, etc. Recebemos junto aos cadernos de atividades, o Livro do Professor com as orientações didáticas sobre o material e um CD musical que auxilia as atividades. Este material é financiado pelo governo federal. Conhecemos mais esse sistema através do site: www.portalaprendebrasil.com.br

8 Vale destacar que o uso deste material é muito criticado atualmente, pois não está em consonância com as indicações das Diretrizes Nacionais da Educação Infantil (2009) que apontam que a proposta da educação infantil, visa dentre outros aspectos a mediação pedagógica elaborada com vistas nas interações e brincadeiras.
} 
quatro e cinco anos. Ambos os grupos ficam em período integral, porém com professoras em horários parciais. Temos ainda a professora de educação física e a professora diferenciada (são assim denominadas/os pelo município as/os professoras/es que preenchem os horários para a hora atividade do/a professor/a regente de sala). A professora de educação física trabalha três vezes por semana, ficando 45 min. em cada turma, nos dois períodos (matutino/ vespertino), e a professora diferenciada, duas vezes por semana, ficando responsável pela turma, também 45min. e nos horários disponíveis nos auxilia em sala. Elas trabalham também no horário do sono, auxiliadas por uma estagiária. O trabalho fragmentado dessas professoras, muitas vezes, limita as proposições pedagógicas com o grupo, em que temos que parar o que estamos realizando, pois está na hora de outra professora realizar sua intervenção. Seria muito mais eficiente e eficaz, tanto para nós professoras quanto para as crianças, se pudéssemos fazer um trabalho articulado, trabalhando em conjunto com grupo, sem a saída de uma professora para a entrada da outra.

Além das seis professoras (duas regentes no período matutino, duas regentes no período vespertino, uma de educação física e uma diferenciada), a instituição conta com uma coordenadora, três estagiárias9 e duas serventes/merendeiras (ambas realizam a limpeza da instituição e preparam a alimentação das crianças).

O horário de funcionamento da instituição é das $7 \mathrm{~h} 30 \mathrm{~min}$. às $17 \mathrm{~h}$ e segue a seguinte rotina: às 8h30min é servido o café da manhã, depois do café as professoras seguem seus planejamentos. Às 10h45min. auxiliamos as crianças na higienização, e seguimos todos/as para o refeitório, onde é servido o almoço, por volta das $11 \mathrm{~h} 20 \mathrm{~min}$ todos já terminaram e seguem para a escovação de dentes.

Cada grupo dorme em sua própria sala, pois não há outro espaço para o momento do descanso/sono. Enquanto as crianças estão almoçando no refeitório,a estagiária do meu grupo coloca dois colchões no chão de cada sala, um de casal e outro de solteiro. Após a escovação as crianças vão para suas respectivas salas e se acomodam nos colchões. O horário designado ao "sono" é das $11 \mathrm{~h} 30 \mathrm{~min}$ às 13h.Quando as professoras e estagiárias do período vespertino chegam,reorganizam as salas e servem frutas às crianças, realizam seus planejamentos, com um intervalo para o café da tarde às $15 \mathrm{~h} 30 \mathrm{mim}$. e a saída das crianças é até às $17 \mathrm{~h}$.

As crianças demonstram, a meu ver, grande prazer em frequentar a instituição, pois, conforme os familiares, elas pedem, com frequência, para ir à instituição, inclusive nos finais de semana. O meu grupo é bem misto em relação à faixa etária, mas há boa interação entre as crianças, percebo isso através das demonstrações de afeto entre elas. Na realização das atividades dirigidas, principalmente as dos cadernos de atividades ${ }^{10}$, as crianças mais velhas costumam auxiliar as mais novas.

Nos momentos de brincadeira, dentro e fora de sala, as crianças brincam muito de faz de conta, em que a brincadeira favorita é a de casinha, com um pai, uma mãe, uma avó, um avô, filhos/as, irmãos/ãs e os animais de estimação, que são representados pelas próprias crianças. Mesmo no pátio da

${ }^{9}$ As estagiárias são, na grande maioria das vezes, jovens do sexo feminino que ainda frequentam o ensino médio, e recebem uma remuneração muito baixa, o que acaba desvalorizando, ainda mais, o trabalho docente.

10 Editora Positivo. 
instituição as crianças continuam as brincadeiras de casinha, porém com a presença e interação do grupo 4. Posto que os maiores assumem os papéis de pai e mãe, representando a autoridade na brincadeira.

As crianças utilizam muito as cadeiras da sala, fechando círculos com elas, e dentro destes círculos ficam as partes da casa, como o quarto, a cozinha, a sala. Quando vão para baixo das mesas, fazem de conta estar dirigindo um carro ou então dizem ser a hora de dormir, como se lá fosse a cama. Nessa brincadeira, eles/as utilizam os brinquedos disponíveis em sala, como bonecas, loucinhas, alguns tecidos, etc. Já no pátio, as crianças preferem brincar sem os brinquedos, e os objetos que utilizam em sala, no pátio são imaginários.

Outra brincadeira muito presente no repertório das crianças é a de salão de beleza (intitulada por elas). Algumas vezes, com poucos itens que caracterizam a brincadeira, as crianças utilizam pecinhas de montar para representar a maquiagem, a "chapinha" de alisar os cabelos, etc. Neste momento, presencio que já há no grupo, principalmente entre as meninas, questões de gênero, pois quando os meninos brincam juntos, sempre são barrados por elas na hora de utilizar maquiagem. Algumas vezes as meninas "fabricam" um batom para meninos, dito por elas incolor. Mas, quando faz parte da brincadeira o batom "real", todos querem passar e quando utilizado pelos meninos, as meninas acham a situação engraçada.

Conforme Daniela Finco (2003, p. 96):

As crianças, capazes de múltiplas relações, estão a todo momento experimentando diferentes formas de brincadeira, buscando novos prazeres, fazendo coisas movidas pela curiosidade e vontade de conhecer o mundo. Na medida em que meninas e meninos transgridem o que é pré-determinado para cada sexo, mostram que a instituição de educação infantil pode apresentar mais uma característica positiva quanto às formas dessas relações: o ambiente da educação infantil pode ser um espaço propício para o não-sexismo.

A grande maioria das crianças que frequenta a instituição mora no mesmo bairro do CMEI. Esse grupo de doze crianças, seis são filhos/as de pais separados, moram com a mãe e o padrasto, ou com a mãe e os avós, uma criança mora com os tios e as outras moram com os pais biológicos. A principal fonte de renda das famílias é a pesca. Enquanto os pais/padrastos pescam, as mães fazem faxinas (limpezas de casas), algumas trabalham no comércio da cidade e outras não têm trabalho remunerado. E três famílias possuem pequenos comércios.

Para descrever esta pesquisa, utilizo registros escritos da minha prática pedagógica a partir da narrativa dos pais, algumas professoras da instituição e das próprias crianças. Optei por não utilizar imagens das crianças (fotografias, vídeos, filmes), também utilizo nomes fictícios para resguardar a identidade delas. Esse encaminhamento metodológico se deu a partir da leitura e alerta que Sônia Kramer (2002) faz ao referir o anonimato das crianças. Segundo ela, esse anonimato deva existir quando coloca a criança ou instituição educativa em situações de risco. Ainda assim, de acordo com a autora, sendo elas sujeitos da pesquisa, como não mencioná-las, e deixá-las ausentes desse processo de ação e produção de suas falas e ações? 
Porém, é importante lembrar que há amparo legal para preservar a identidade da criança e do adolescente. Para nosso ordenamento jurídico, a criança e o adolescente são incapazes de responder pelos seus atos ${ }^{11}$, e fica visível que tal exposição poderá gerar situações indesejadas. Desta forma, há, evidentemente, um choque de direitos, cabendo ao/à pesquisador/a ponderar qual medida tomar. Kramer (2002) em seu texto "Autoria e autorização: questões éticas na pesquisa com crianças.", sugere que as crianças sejam consultadas e avisadas da pesquisa.

Durante todo o processo de registros as crianças estavam cientes de que eram observadas. No início não davam importância, pois é rotineira a utilização do registro (escrito e fotográfico, mas utilizarei apenas os registros escritos, pois não obtive autorização da instituição para exposição dos registros fotográficos) em meu cotidiano, desta forma, elas estavam acostumadas com este procedimento.

Conversei com o grupo dizendo a eles/as que eu estava fazendo uma pesquisa, a qual os envolvia, por isso precisava anotar o que acontecia em nosso grupo em meu caderno de registros. Contei-lhes que algumas de suas falas eram transformadas em escritas, e,se permitissem, gostaria de utilizá-las em minha pesquisa, e que posteriormente outras pessoas iriam ler o que acontecia com nosso grupo. Li alguns registros às crianças para que elas entendessem melhor o que eu falava. A maioria gostou da ideia, algumas não deram importância. Com isso combinamos de escolher nomes fictícios, sendo que alguns foram sugestões minhas, pois a maioria das crianças repetia o que a/o colega escolhia.

\section{Iniciando o diálogo com os/as informantes}

Em minha concepção de professora e pesquisadora, a criança, enquanto sujeito histórico, tem seu modo próprio de compreender o meio em que está inserida, e participa ativamente da construção social e cultural. Essa ideia é bastante abordada atualmente, mas é sabido que as crianças do final do século XX e início do século XXI vivem infâncias que se diferenciam de séculos passados, em que a criança era tida como um ser passivo, receptora apenas de conhecimentos proporcionados pelo mundo adulto.

Segundo as autoras Rodrigues, Borges e Silva (2014, p. 271):

[...] criança, enquanto um ser biológico, sempre existiu tratando-se da pessoa de pouca idade e que teve um papel diferenciado ao longo da história da humanidade e nos diversos contextos sociais e culturais. Entretanto, é importante destacar que, apesar dessa reconhecida existência, nem sempre a criança foi entendida como ator social que pensa, reflete, discute, argumenta, elabora juízos de valor, etc.

Através das construções históricas e culturais, encontram-se diferentes concepções do que significa ser criança, de suas especificidades e de como elas vivem suas infâncias. Deste modo, percebe-

\footnotetext{
${ }^{11}$ Lei nº 10.406 - Código Civil.
} 
seque as crianças não pertencem a uma única infância, pois a infância é idealizada pela cultura em que a criança está inserida, e são múltiplas as culturas, assim como também são múltiplas as infâncias.

[...] a partir dos processos histórico-sociais e das relevantes contribuições de diversas áreas do conhecimento, hoje, acriança é vista como um sujeito concreto que integra uma categoria geracional; uma construção social que, com o passar do tempo, se transforma, variando entre grupos sociais e étnicos dentro de qualquer sociedade. Essas formas diferenciadas de se ver e de tratar esses seres de pouca idade é o que chamamos de 'infância'.Ou seja, infância é a forma de ser criança, ou melhor, as formas, pois, a partir dessa definição, não teremos mais uma única infância e, sim, infâncias. Essas formas de se ver e conceber os diversos tipos de infância fazem parte de um processo histórico-cultural que foi sendo construído e modificado em diferentes tempos, espaços e sociedades (RODRIGUES, BORGES e SILVA, 2014, p. 271-272).

Com o passar do tempo e conforme as transformações sociais acontecem, cada vez mais as crianças são objetos de estudo, pois há uma grande necessidade de entendê-las em suas diferentes particularidades, busca-se "apreender e dar visibilidade ao ponto de vista da criança, reconhecendo-a como protagonista das suas experiências" (CRUZ, 2004, p. 3).

Estudos realizados por áreas como a psicologia e a pediatria demonstram que essa visibilidade é resposta de um avanço social para a história da criança e da infância, apesar de ser criticada ao longo dos anos pelos estudos da infância, pela centralidade na perspectiva desenvolvimentista, por exemplo. Ainda que incompleta, essa resposta é uma conquista histórica, tendo a garantia de direitos em documentos legais, como a Constituição Federal de $1988^{12}$ e o Estatuto da Criança e do Adolescente (ECA) 199013, bem como o alargamento dos estudos da pedagogia, sociologia e antropologia da infância. Segundo Kramer (2002), "a visão de criança baseada numa suposta natureza infantil, e não na condição infantil, mascara a significação social da infância". Ou seja, a criança, enquanto sujeito, se constitui com o outro, com os adultos e/ou seus pares, sendo ao mesmo tempo ativa e criativa neste processo, e não apenas passiva, ela interfere no meio em que está inserida, mesmo vivendo em uma sociedade adultocêntrica, ela vive a cultura e a transforma.

Ressalto que a sociedade tem essa visão adultocêntrica, pois predomina a perspectivado adulto sobre a criança. Nessa visão, a criança vive em expectativa do futuro, o que ela será, e há, desta forma, a impossibilidade de olhar para criança no presente, em suas especificidades da infância, a compreensão de seus gestos, movimentos, expressões, narrativas (DELGADO e MÜLLER, 2005).

Contrária à lógica adultocêntrica, já criticada pelos estudos da área, e considerando a construção histórica da infância, utilizo nessa pesquisa e apresento a seguir, não só as narrativas de pais e professoras, mas também das crianças, por elas serem partícipes deste processo.

\footnotetext{
${ }^{12} \mathrm{~A}$ Constituição, também conhecida como Carta Magna, é a lei suprema e fundamental do Brasil e se situa no topo de todo o ordenamento jurídico. Ou seja, nenhuma lei pode contrariar o que está determinado nela. Disponível em: http://www.promenino.org.br/direitosdainfancia/eca-e-legislacao.

${ }^{13}$ No ECA estão determinadas questões como os direitos fundamentais das crianças e dos adolescentes; as sanções, quando há o cometimento de ato infracional; quais órgãos devem prestar assistência; e a tipificação de crimes contra criança. Disponível em: http://www.promenino.org.br/direitosdainfancia/eca-e-legislacao.
} 


\section{O que as famílias nos contam}

As crianças são levadas a instituição por seus familiares, desta forma sempre tenho um relato das famílias, principalmente das mães ${ }^{14}$, do que acontece com as crianças em casa ou em outros momentos fora da instituição. Assim, trago aqui um comentário realizado pela mãe de Bia (3 anos), em uma manhã que ao chegar na instituição encontra apenas Lilo, seu colega da mesma idade, na sala.Ela diz: "Ãn sua sem vergonha, vai ficar só tu e ele (Lilo) é?!”. A mãe de Bia, que incita o flerte entre ela e o colega, denomina-a de sem vergonha. Vale pensar: Porque a interação entre um menino e uma menina, ou seja, entre as crianças, causa tais reações nos adultos?

Percebo também que há conversas entre as famílias das duas crianças, sobre o possível "namoro" (assim descrito por uma mãe, conforme baixo) entre elas. E a mãe da menina, mesmo achando a situação "engraçada”, aparenta certa preocupação. Há implicitamente um receio que possa acontecer de fato um namoro entre as crianças?

Já a mãe de Lilo, ao narrar uma conversa com seu filho, mostra-se orgulhosa por ele demonstrar seu "encanto" pela colega. Ela diz: "Ele fala: A Bia é a mais bonita, eu namoro com ela, beijo a boca dela". Risos... Visse como ele não é bobo nem nada?

Com essa narrativa, ponho-me a pensar: Se Lilo demonstrasse afeto por outro menino, seria ainda assim um motivo de orgulho para sua mãe?

[...] o que nos leva a pressupor que partilham do processo de construção da sexualidade do indivíduo suas observações, os ensinamentos e informações adquiridos no contexto familiar, no senso comum, nos diálogos e no contexto escolar, incluindo neste último as concepções do docente referente à temática da sexualidade (MEIRA e SANTANA, 2014, p. 162).

Esses e outros comentários cotidianos nos fazem refletir que a sexualidade faz parte de um processo de construção social, e que ocorre desde o nascimento do ser humano, pois é a partir daí que as informações e conhecimentos sobre as relações corpóreas e afetivas são construídas, inclusive no meio familiar, decorrentes de sua cultura (MEIRA e SANTANA, 2014). Nos comentários acima, há este exemplo do modo como significam o conhecimento cultural, o qual desde cedo são mediadas e expressas pelas crianças. Essa cena, narrada no acolhimento das crianças, parece que a interação e afeto entre os corpos dos pequenos, podem ser entendidos pelo olhar do adulto como algo atrelado ao namoro. $\mathrm{Na}$ sequência, a narrativa do menino reitera a demarcação da mãe. E aqui, me pergunto como professora, como posso trazer outro olhar para compreender a cena, as narrativas da criança e das famílias a partir da lógica de interação entre os corpos das crianças, contrária a essa lógica erotizada e que rompam com a lógica heteronormativa?

${ }^{14}$ A grande maioria das crianças é levada à instituição pelas mães, que dispõem deste horário livre ou por fazer parte de seu trajeto para o trabalho. 


\section{Receio referente à orientação sexual?}

A instituição onde trabalho, como dito anteriormente, é um espaço muito pequeno, não possui área de lazer externa coberta, portanto, as crianças brincam mais em sala, principalmente nos dias chuvosos. Devido ao tamanho de nossa sala, as crianças, por vezes, brincam embaixo das mesas, onde formamos barracas.

Em certa manhã, uma mãe muito aflita veio a mim perguntando se havia algum colega de Bin (seu filho, 3 anos de idade) chamado Léo (2 anos), este por vez já estava na sala. Quando ela o viu, exclamou: "Nossa! Ele já tem cara de safado!". Relatou-me então, que seu filho Bin, havia reclamado que o amigo "mexia" em seu "bumbum". Ela me pediu:

Prof.. observa o Bin, sabe, ele anda mexendo no bumbum, e dir que o Léo coloca a mão no bumbum dele. Olha isso pra mim? Já briguei com ele em casa. Disse a ele que isso não pode fazer, é feio. Só a mamãe, a vovó e a prof. podem mexer no bumbum dele, para limpar. Ninguém mais... fico com medo que ele acabe gostando, achando que isso é normal e que qualquer pessoa possa mexer no bumbum dele (Dado de campo - Mãe de Bin, 2015).

Neste comentário, a mãe expressa preocupação em pensar que seu filho sinta prazer anal, implicitamente apresentando receio à orientação sexual. Ou ainda, inicialmente, por não conhecer Léo, demonstre medo à pedofilia, talvez por pensar, que Léo seja um adulto que trabalhe ou frequente a instituição.Fiquei me perguntando ao analisar o comentário da mãe de Bin ao conhecer Léo: Acha ela que as atitudes dele com seu filho são libidinosas? E não, que façam parte da fase de seu desenvolvimento?

Pode-se perceber também que a sexualidade não é algo natural, e sim construído através do meio cultural em que cada ser está inserido. Para Louro (2000, p. 6): “[...] podemos entender que a sexualidade envolve rituais, linguagens, fantasias, representações, símbolos, convenções... Processos profundamente culturais e plurais". Ou seja, a sexualidade é formada socialmente, e não exclusivamente natural a todo ser humano, enquanto criança a sexualidade representa também uma forma de descoberta de prazer, a criança ao se tocar está descobrindo uma área prazerosa em seu corpo, diferente do adulto que já possui uma carga social referente a conceitos sexuais, pelo processo de informações e conhecimentos que lhe são transmitidos ao longo de sua vida.

Assim, enquanto professora, pensei sobre as possíveis maneiras de auxiliar a mãe de Bina pensar com ela que existem outros modos de dialogar com seu filho sobre o que aconteceu, sobretudo para que nós duas pudéssemos esclarecer à criança que não é feio mexer em seu bumbum, mas que é importante que ele saiba que aos poucos ele vai tocar em seu corpo e dará limites para que outras pessoas o toquem.

\section{Sentidos atribuídos pelas profissionais: descoberta do corpo?}


Durante o horário do sono, que acontece das $11 \mathrm{~h} 30 \mathrm{~min}$ às $13 \mathrm{~h}$, ficam em sala com as crianças a estagiária e uma professora, a professora diferenciada ou a de educação física. É denominado horário do sono, mas as crianças não são forçadas a dormir, no entanto, todas que ficam na instituição em período integral participam deste momento. Em um destes momentos, a professora visualizou duas crianças se tocando, ela interviu pedindo para que o menino parasse de incomodar a colega da mesma idade. A menina disse a ela que não era incomodo e que estava gostando. A professora trocou as crianças de lugar, colocando-as longe, naquele momento, e narrou para mim a seguinte situação: Guria, nem te conto, esses dias, na hora do soninho, o Léo estava mexendo na vagina da Maria,e ela
estava gostando. Será que eles veem em casa? Troquei eles de lugar, fiquei chocada. (Dado de campo
- professora diferenciada, 2015).

Situações como essas retratam a necessidade discussões sobre gênero e sexualidade para complementar nossa formação enquanto professoras de educação infantil, para que saibamos lidar com essas circunstâncias, devido ao fato de as crianças também aprenderem a se relacionar com seus corpos, a partir de mediações pedagógicas expressas no silêncio e no olhar revelador da professora.

Com este relato, colocando-me no lugar da professora, penso qual atitude seria a minha. Trocaria as crianças de lugar também se o meu pedido para que parassem não fosse aceito? Como as crianças podem ter interpretado a atitude da professora?

São essas e outras questões que fazem com que a sexualidade seja "guardada". Evita-se falar sobre o assunto, pois para muitas profissionais e também famílias, falar sobre sexualidade estimulará o desejo e o prazer sexual, algo veementemente censurado, já que se parte do pressuposto de que as crianças não devem interagir com situações que lhes "despertem” para a sexualidade. Como analisam Guizzo e Felipe (2015, p. 8):

[...] enquanto professores/as e educadores/as, é muito provável que nossos posicionamentos e opiniões produzam efeitos sobre nossos alunos. Então, mesmo que não intencionalmente, várias situações com as quais nos envolvemos e colocamos em prática ensinam e dizem sobre gênero, sexualidade, diferença e educação.

A situação ocorrida entre as crianças foi relatada a mãe de Léo, que se mostrou surpresa e um pouco nervosa, dizendo:

Nossa! Não acredito. Mas ele não vê nada disso em casa. Peço que não conte isso pra mãe da menina, senão o pai dela vai vir querer tirar satisfação. Risos... (Dado de campo - Mãe de Léo, 2015).

O que leva a mãe a justificar que seu filho não vê essa situação no espaço doméstico? Os pais, na grande maioria das vezes, não acreditam em sexualidade infantil, e tais descobertas e certas curiosidades expressadas pelas crianças não façam parte de seu desenvolvimento. Aqui, mais uma vez, ponho-me a refletir o quanto seria conveniente que a instituição educativa dialogasse com estes pais com a finalidade de fazê-los compreender o desenvolvimento infantil em suas dimensões afetivas e sexuais. Pois eles 
tendem a crer que a sexualidade corresponde apenas à reprodução do universo familiar, e, desta forma, para que haja alguma representação de sexualidade entre crianças, estas precisam se espelhar em modelos e copiar os gestos dos adultos. Ou ainda, conforme Guizzo e Felipe (2015 p. 11):

[...] afirmamos que as famílias parecem não se dar conta de que a educação acontece em diferentes meios, como a televisão, os jornais, a internet, entre tantos outros meios que poderiam aqui ser citados. Elas parecem acreditar que a educação restringe-se ao espaço escolar. Sendo assim, se aí não se falar de sexualidade, as crianças e os jovens que por ela circulam não se interessarão por essa questão.

Como já visto, mesmo que implicitamente, a sexualidade é discutida pelas famílias e também na instituição, mas a sexualidade falada é a aquela que está dentro da lógica heteronormativa(NOGUEIRA, 2015), quando fere este conceito é explicitamente evitada.Trago aqui um comentário realizado por outra professora da instituição durante uma reunião pedagógica:

$V$ amos proibir que entrem meninos e meninas juntos no banbeiro para não ficar uma situação "chata", eles tem que aprender que não podem ficar vendo o outro pelado. (Dado de campo professora do G4, 2015).

Há diferentes interpretações desta fala. Este comentário se deve ao interesse em ensinar noções de intimidade e/ou a diferenciação entre os sexos, ou evitar possíveis questionamentos sobre o sexo oposto?

Como a sexualidade infantil coloca em xeque o sistema normativo de instituições educativas, historicamente normalizadora, há uma fuga constante deste assunto. Como nos afirma Souza (2015), as instituições educativas são, por sua vez, locais em que se pretende controlar o que se refere à sexualidade, tratando-a com traquejo e discrição e, que essa vontade de dessexualização do espaço educacional, mesmo que ainda muito presente, é um obstáculo bastante difícil de ser transposto, sobretudo quando a sexualidade ainda for vista como impureza, perversão ou mesmo pecado.

Conforme Meira e Santana (2014, p. 169):

[...] o docente, sujeito histórico-cultural que tem em sua prática o reflexo da sua compreensão de homem e de mundo, sendo necessário manter um posicionamento reflexivo, respeitoso e medidor uma vez que há de se confrontar com diferentes conflitos e dúvidas sexuais que precisam ser trabalhadas de maneira significativa respeitando o desenvolvimento de seu aluno [...].

Sendo assim, vale pensar que o/a docente não precisa ser especialista em educação sexual, mas sim mediador/a do conhecimento enquanto profissional da educação e possuir no mínimo informações sobre a sexualidade infantil para que evite situações constrangedoras e auxilie as crianças a esclarecer seus decorrentes questionamentos. 
Naquela mesma manhã em que recebi a queixa da mãe de Bin, observei quando as crianças foram brincar em baixo da mesa e pediram para que eu fizesse uma barraca. Auxiliei na construção da barraca utilizando panos e mantas. Os meninos foram correndo para debaixo da barraca enquanto as meninas preparavam algumas bonecas e outros brinquedos para juntarem-se a eles. Neste momento, "dentro" da barraca, observei que Bin pedia para um colega colocar massinha de modelar em seu "bumbum", como havia mais crianças no mesmo local, também se interessaram em fazer o mesmo.

As crianças observaram que eu estava presente, riram entre elas e sem conversa começaram a brincar de "casinha" juntamente com as meninas.

Mais tarde, na mesma manhã, Bin pediu para que outra criança do grupo introduzisse uma peça de lego em seu "bumbum". Neste momento, pedi para que o amigo Lilo não o fizesse, pois isto machucaria Bin. Perguntei o que estava acontecendo e Bin disse que era nada, ficando nervoso e constrangido. Conversei com Bin e Lilo, explicando que aquele tipo de brincadeira poderia machucá-lo, por se tratar de uma parte sensível do corpo. Ambos entenderam e juntaram-se ao restante do grupo.

Essa brincadeira pode ser pensada a partir das discussões que Guimarães (2012) realiza ao analisar as concepções freudianas sobre a sexualidade infantil, em que confirma que as relações corpóreas afetivas podem ser pensadas a partir da dimensão biológica, mas essa vai se transformando culturalmente pelo ser humano. A sexualidade infantil apresenta-se através de pulsões, e algumas dessas pulsões percorrem etapas até a vida adulta, como define a citação a seguir:

$\mathrm{Na}$ infância, as pulsões parciais são desvinculadas e independentes entre si em sua busca do prazer, não subordinadas ao primado da genitalidade. Essas pulsões precisam percorrer etapas, caminhos que culminam na sexualidade adulta, na qual as pulsões se unem a serviço da função reprodutora e com a finalidade de atingir um objeto sexual.A pulsão sexual, que era inicialmente autoerótica, desloca-se à procura de um objeto. Nesse sentido, o autoerotismo, como momento originário da sexualidade, obriga-se a dar lugar ao objeto de satisfação situado fora dos limites do sujeito (GUIMARÃES, 2012,p. 54).

Também Paula Costa (2012) retoma a Teoria do Desenvolvimento da Sexualidade, pensada a partir da perspectiva freudiana, explicita/reconhece que esse período do desenvolvimento pode haver a descoberta de prazer através dos órgãos genitais, por isso intitulada pelas discussões psicanalistas defase fálica, percurso do desenvolvimento em algumas vezes as crianças ficam atentas e curiosas inclusive pelo modo como denominamos as genitálias. Essa autora descreve que, algumas vezes, a criança imagina que as meninas também possuem pênis, mas que este órgão lhes foi arrancado, a partir definição freudiana de complexo de castração. Além dessa descrição, é interessante pensar que uma das contribuições da psicanálise resulta exatamente na possibilidade de perceber que o toque do seu corpo e o corpo do outro,pode fazer parte do percurso do desenvolvimento.

Com base nisso, exponho um registro de uma ida ao banheiro com Bin ( 3 anos) e Maria ( 2 anos). Bin fica surpreso ao observar que Maria não possui pênis. Assustado ele pergunta: "Prof., porque a Maria não tem pipi? Ela perden o pipi?”. 
Seguindo as contribuições freudianas, percebo que além do controle dos esfíncteres, característica da idade, é necessário levar em conta a singularidade das crianças,de seu desenvolvimento biológico, cultural e social.A grande maioria das crianças apresentam muita curiosidade pelas áreas genitais, tanto as deles quanto as dos colegas. Um exemplo disto acontece com Léo (2 anos) que, em brincadeira livre em sala, observa seu pênis e pede para os colegas mostrarem os seus, dando risada quando eles atendem ao seu pedido.

Em outro momento,com o grupo bem disperso, observo Léo (2 anos) e Emilly (3 anos). Ele se deita sobre Emilly, que já está deitada no chão, fazendo o movimento de abertura das pernas dela e movimentando a sua pélvis. Emilly parece estar desconfortável e ao mesmo tempo não revela estar incomodada com a situação. Peço para que Léo saia de cima da colega, pois poderá machucá-la. Emilly responde: "É meu marido, prof., meu amiguinho!".

Léo continua sem interesse em minha fala. Depois, Emilly o empurra e Léo já se distrai com os outros colegas.

A resposta de Emilly faz representação à imitação do modelo adulto feito pelas crianças? Conforme Delgado e Müller (2005, p. 6) "Por não serem seres passivos, as crianças reproduzem a cultura dos adultos através de uma interpretação que lhes é própria.”. Ferreira (2004) também descreve como as crianças apresentam elementos do cenário doméstico, midiático, cultural, do qual a criança está inserida e ao mesmo tempo apresenta o quanto as crianças resignificam esses elementos.

Ao retomar a documentação pedagógica, percebi que curiosidade e dúvidas que algumas crianças apresentavam em relação ao sexo oposto, por isso realizei a seguinte proposição pedagógica:

Combinamos (eu e o grupo) de banhar os "bebês" (duas bonecas de sexo oposto, ou seja, uma com vagina e outro com pênis), mas o bebê do sexo masculino era surpresa para as crianças. Começamos a conversa falando da importância de tomar banho, sentamo-nos no chão em formato de "roda", colocamos ao meio uma banheira com água morna, shampoo, sabonete e duas toalhas.Acordamos que todos poderiam banhar os bebês, mas da seguinte forma, de dois em dois, para que não criasse tumulto. Duas crianças prontamente se aproximaram, estas ficaram responsáveis por despir os bebês e colocá-los na banheira. Ao retirar as roupas das bonecas houve muitas risadas e comentários. Bin: "É menino, é menino... ele tem pipi e essa é menina porque ela tem "pepeca"”.

Assim fomos banhando os bebês e pude conduzir a conversa dizendo que na hora do banho devíamos lavar muito bem nossa vagina e os meninos o pênis, pois esta parte de nosso corpo é sensível e precisamos tomar algumas precauções na hora de tocá-las.

Durante toda a conversa as crianças iam banhando os bebês e prestando muita atenção ao que ouviam. Dialogamos que para tocar em nossas genitálias, temos que estar com as mãos limpas para que não haja nenhum tipo de "machucado", pois mãos sujas levam a sujeira para onde tocamos e como as genitálias possuem uma pele sensível, a sujeira das mãos ou até mesmo as unhas podem causar machucados. Desta forma, o melhor momento de nos tocarmos é na hora do banho. Sendo que, em momento nenhum lhes disse que o toque era proibido, pois de acordo com Costa (2012, p. 87) "A auto 
exploração é uma outra experiência fundamental. Pelo tato a criança descobre que tem órgãos especialmente sensíveis que produzem sensações agradáveis. Desse modo aprende a brincar e a obter prazer com o seu corpo." Como pensar nas mediações pedagógicas quando se trata das relações corpóreas para além do cuidado com o corpo/higiene e para além das diferenças biológicas?

Algumas meninas lavavam com muito cuidado o pênis do "bebê", outras nem tocavam, enquanto os meninos riam muito quando chegavam nessa parte. Já com a "bebê" do sexo feminino, eles banhavam normalmente, tanto os meninos quanto as meninas, talvez pelo fato de estarem mais acostumados com as bonecas, que em grande maioria são representadas pelo sexo feminino.

Essa atividade se deu pelo interesse expresso pelas crianças em relação ao sexo oposto, mas acredito que para a sexualidade ser um tema abordado em todas as suas concepções, biológica, históricas e culturais, o papel do/a professor/a é ampliar e não restringir as mediações a lógica higienicista ou mesmo a concepção biológica, problematizando os aspectos culturais e históricos que percorrem a sexualidade. Há muitos meios de abordar a sexualidade infantil com as crianças, como a diferença corporal entre meninas e meninos, pois é possível demonstrar às crianças que não há nada de errado em possuir pênis e brincar de boneca, ou em possuir vagina e jogar futebol, por exemplo, ou também, através da privacidade de cada corpo, dos diferentes arranjos familiares, das linguagens e formas de se referir as genitais, bem como modos diversos de cobrir os corpos em diferentes culturas. Assim, perceber como as crianças entendem essas diferenças corporais e sexuais, e como elas lidam com essas questões, para que a mediação do/a professor/a seja intencional e produtiva.

\section{Considerações finais}

O foco do artigo foi analisar como as profissionais e os familiares das crianças de meu grupo lidam e se posicionam com as questões relacionadas à sexualidade infantil, bem como as narrativas dos familiares e professoras, na tentativa de entender o os significados dos adultos e suas idealizações em frente ao universo infantil, para depois apresentar os registros das crianças e mostrar o quanto elas são participes nesta perspectiva. Buscando, deste modo, revelar como as crianças são ativas e transformadoras da cultura em que estão inseridas.

No decorrer da realização desta análise crítica da prática pedagógica, pude perceber como,cada vez mais,minhas dúvidas e questionamentos ao redor da sexualidade infantil cresciam, mesmo sendo este um aspecto central da vida do ser humano, por se tratar de um tema rodeado de tabus.

Por mais que este tema seja evitado, ele aparece nas entrelinhas do discurso corriqueiro de famílias, no interior das instituições educativas e entre as crianças. Elas, por sua vez, acreditam, penso eu, que falar algo que designe a sexualidade deva ser evitado, mas os próprios familiares o fazem (a sexualidade aqui referida é apenas a que diz respeito às normas sociais, ou seja, a sexualidade heteronormativa) sem se dar conta dos conceitos e preconceitos que transmitem às crianças. 
Pude perceber, através das narrativas, que as professoras e familiares ficam em um impasse entre o que é certo e o que é errado referente à sexualidade infantil, em que uma teme esbarrar nos conceitos da outra.

As crianças participam desse impasse, demonstrando isso em suas narrativas e comportamentos. Algumas reproduzem uma sexualidade proibida, como no caso de Bin, por ouvir de sua mãe que é errado mexer em seu bumbum, ele define como errado algo atrelado ao prazer com seu corpo e o corpo do outro. Já na situação ocorrida entre Léo e Maria, quando flagrados na hora do sono se tocando, não se demonstraram incomodados com a presença das demais pessoas em sala, talvez por nunca terem sido repreendidos e não relacionarem essas ações como algo proibido.

A sexualidade, apesar de fazer parte de todo o processo de desenvolvimento do ser humano, ou seja, desde o nascimento até a morte, transitando por diferentes fases, culturas, religiões, etc., ainda é um tema que causa polêmica entre as instituições educativas e família. Segundo Costa (2012, p.82), "Sendo a sexualidade parte integrante e integradora de todos os seres humanos, é uma componente basilar e fundamental para o seu bem-estar pessoal, interpessoal e social.”. E assim sendo, é fundamental que esta seja trabalhada na educação infantil, etapa da vida em que este tema é muito questionado por se tratar de um período em que a criança está descobrindo seu corpo e as maneiras de sentir prazer através dele, e que também está atenta às mudanças e diferenças entre os sexos.

Mas mostrar aos familiares e também à própria instituição educativa que a sexualidade faz parte dos direitos da criança, devendo ser abordada em suas diferentes concepções, ainda que amparada legalmente,não é tarefa simples, mesmo quando cientes deste direito, na grande maioria das vezes, os olhares são fechados e os ouvidos silenciados, principalmente nas instituições de educação infantil.

Desta forma, percebo que há grande necessidade de que na formação inicial e continuada, se aprofunde as temáticas e discussões sobre gênero e sexualidade, para que os/as professores/as disponham dos conhecimentos necessários para trabalhar a sexualidade em todas as suas concepções, biológica, histórica e cultural. E assim, oferecer as crianças e também aos seus familiares, informações além daquelas já existentes, e esclarecer dúvidas e possíveis equívocos para que instituições educativas e família caminhem juntas no desenvolvimento integral dos/as pequenos/as.

Por meio da análise das situações ocorridas em meu cotidiano, trouxe para este texto algumas reflexões, acreditando que possam contribuir para que muitos/as professores/as reflitam também sobre suas práticas. Sendo que muitos/as passam pelas mesmas situações e questionamentos cotidianamente, assim como eu.

O foco desta análise crítica foi em meu grupo de crianças, mas ela pode ser desenvolvida em outras realidades (Instituições, faixas etárias), e, através dos resultados obtidos, quem sabe, corroborar com outras análises e pesquisas e até mesmo servir de apoio as/os profissionais e familiares envolvidos.

Enfim, neste trabalho não tive a intenção de trazer respostas a cerca da sexualidade infantil. Mas sim, novas maneiras de pensar e repensar as práticas de trabalhá-la na educação infantil. 


\section{Referências}

ASINELLI-LUZ. A., DINIS. N.. Educação sexual na perspectiva histórico-cultural. Educar, Ed. UFPR,n. 30, Curitiba, 2007. p. 77-87. Disponível em: <http://www.scielo.br/pdf/er/n30/a06n30.pdf>. Acesso em: 13 dez. 2015

BRASIL. Lei de Diretrizes e Bases da Educação Nacional. Lei no 9394, de 20 de dezembro de 1996. Disponível em http://portal.mec.gov.br/arquivos/pdf/ldb.pdf. Acesso em: 12 set. 2015.

Ministério da Educação. Conselho Nacional da Educação. Diretrizes Curriculares Nacionais Gerais para a Educação Básica. Brasília: DF, 2010.

Ministério da Educação e do Desporto. Secretaria de Educação Fundamental. Parâmetros Curriculares Nacionais. Brasília: MEC/SEF, $1997 . \quad$ Disponível em: <http://portal.mec.gov.br/seb/arquivos/pdf/livro01.pdf> Acesso em: 14 jan. 2016.

CARVALHO.Cibele N.Palavrão é tudo que tem no corpo de Deus um estudo sobre o obsceno das crianças. In:37 ${ }^{a}$ Reunião Nacional da ANPEd 2015, Florianópolis.UFSC. Disponível em: <http://37reuniao.anped.org.br/wp-content/uploads/2015/02/Trabalho-GT07-4270.pdf> Acesso em: 20 dez. 2015.

CÉSAR.Maria Rita de Assis.Gênero, sexualidade e educação: notas para uma “Epistemologia”.Educar, Ed. UFPR,n. 35, Curitiba, 2009.p. 37-51. Disponível em:<http://www.scielo.br/pdf/er/n35/n35a04.pdf>Acesso em: 13 dez. 2015.

COSTA. Paula C. A.Sexualidade na primeira infância:um percurso que se inicia na família. Contextoe Educação.Ed. Unijuí. Ano 27 no 88 Jul./Dez. 2012.

CRUZ, Silvia Helena V. Ouvindo crianças: considerações sobre o desejo de captar a perspectiva da criança a cerca da sua experiência educativa. In: $27^{a}$ Reunião Anual da ANPED. Anais... Caxambu, 2004. Disponível em:<http://www.anped.org.br/reunioes/27/gt07/t078.pdf> . Acesso em: 13 fev. 2013.

DELGADO, Ana C. C. MÜLLER, Fernanda. Abordagens etnográficas nas pesquisas com crianças e suas culturas. Anais da $28^{\circ}$ Reunião da ANPED,2005.

FERREIRA. Maria Manuela M. A gente gosta é de brincar com os outros meninos! Relações sociais entre crianças num jardim de infância. Afrontamento. Portugal, 2004.

FINCO. Daniela.Relações de gênero nas brincadeiras de meninos e meninas na educação infantil. Pro-Posições. v.14, n. 3 (42) - set./dez. 2003. Disponível em: <http://www.cppnac.org.br/wpcontent/uploads/2013/07/Rela\%C3\%A7\%C3\%B5es-de-genero-nas-brincadeiras-de-meninos-emeninas.pdf $>$ Acesso em: 15 abril. 2016.

GENERO E DIVERSIDADE NA ESCOLA: formação de professores/as em gênero, orientação sexual e relações étnico-raciais.livro de conteúdo. Versão 2009 - Rio de Janeiro: CEPESC; Brasília: SPM, 2009. Disponível

em: <http://estatico.cnpq.br/portal/premios/2014/ig/pdf/genero_diversidade_escola_2009.pdf.>. Acesso em: 9 nov. 2015.

GUIMARÃES. Veridiana Canezin. A concepção Freudiana da sexualidade infantil e as implicações da cultura e educação. Revista educativa, v. 15, n. 1, Goiânia, jan./jun. 2012. p. 53-66.

GUIZZO. B. S., FELIPE. J. Avanços e retrocessos em políticas públicas contemporâneas relacionadas a gênero e sexualidade: entrelaces com a educação. In:37 Reunião Nacional da 
ANPED,Florianópolis, UFSC. 2015. Disponível em: <http://37reuniao.anped.org.br/wpcontent/uploads/2015/02/Trabalho-GT23-3858.pdf> Acesso em: 20 dez. 2015.

KRAMER, Sônia. Autoria e autorização: questões éticas na pesquisa com crianças. Cadernos de Pesquisa, RJ, n. 116, julho/ 2002. p. 41- 59. Disponível em: <http://www.scielo.br/pdf/cp/n116/14398.pdf> Acesso em:16 fev. 2016.

LOURO. Guacira L. (org.) O corpo educado: Pedagogias da sexualidade. Ed. Autêntica, $2^{\mathrm{a}}$ ed. Belo Horizonte, 2000.

MARIANO,C. L. S., OLIVEIRA. E. S. A., SALGADO. R. G. Entre a inocência e o profano: a sexualidade na infância contemporânea. In: $37^{a}$ Reunião Nacional da ANPED,Florianópolis, UFSC, 2015. Disponível em: <http://37reuniao.anped.org.br/wp-content/uploads/2015/02/Trabalho-GT074587.pdf> Acesso em: 20 dez. 2015.

MEIRA R. D., SANTANA L.T. Sexualidade na perspectiva histórico-cultural: primeiras aproximações.In: Trilhas pedagógicas, v. 4, n. 4.Ago. 2014. p. 160-181. Disponível em:<http://www.fatece.edu.br/arquivos/arquivos\%20revistas/trilhas/volume4/11.pdf $>$. Acesso em: 8 nov. 2015.

NOGUEIRA.Juslaine de F. A.Dispositivo da sexualidade e psiquiatrização da educação: notas farmacobiopolíticas sobre o corpo. In: $37^{a}$ Reunião Nacional da ANPED, Florianópolis,UFSC.2015. Disponível em: <http://37reuniao.anped.org.br/wp-content/uploads/2015/02/Trabalho-GT234429.pdf> Acesso em: 20 dez. 2015.

PARREIRA. F. L. D., SILVA. E. P.Q. Discursos de bolsistas do programa institucional de bolsa de iniciação à docência sobre sexualidade. In: $37^{a}$ Reunião Nacional da ANPED, Florianópolis,UFSC.2015. Disponível em: <http://37reuniao.anped.org.br/wpcontent/uploads/2015/02/Trabalho-GT23-4538.pdf> Acesso em: 20 dez. 2015.

RODRIGUES, S. A. BORGES, T. F. P. SILVA, A. S. Com olhos de criança: a metodologia de pesquisa com crianças pequenas no cenário brasileiro. Nuances: estudos sobre educação. Presidente Prudente. SP, v. 25, n. 2, maio/ ago, 2014 p. 270-290.Disponível em: <http://revista.fct.unesp.br/index.php/Nuances/article/viewFile/3188/2698> Acesso em: 10 mar. 2016.

SANTA CATARINA. Governo do Estado. Secretaria de Estado da Educação. Proposta Curricular de Santa Catarina: formação integral na educação básica. 2014. Disponível em: $<$ http://www.propostacurricular.sed.sc.gov.br/site/Proposta_Curricular_final.pdf $>$ Acesso em: 20 dez. 2015.

SOUZA. Marcos L.O PIBID como espaço formativo de desarranjos, reinvenções e pluralizações dos gêneros e das sexualidades.In: $37^{a}$ Reunião Nacional da ANPEd,Florianópolis, UFSC. 2015. Disponível em: <http://37reuniao.anped.org.br/wp-content/uploads/2015/02/Trabalho-GT233732.pdf> Acesso em: 20 dez. 2015.

TUCKMANTEL. M. M. A sexualidade vai à escola: da informação biológico-reprodutiva à formação do sujeito ético. In: Trilhas pedagógicas, Pirassununga, v. 1, n. 1, p. 38-62, ago. 2011. Disponível em: $<$ http://www.fatece.edu.br/arquivos/arquivos\%20revistas/trilhas/volume1/3.pdf $>$. Acesso em: 8 nov. 2015.

ZORNIG. S. M. A. As teorias sexuais infantis na atualidade: algumas reflexões.Psicologia em Estudo, Maringá, v. 13, n. 1, p. 73-77, jan./mar. 2008. Disponível em:<http://www.scielo.br/pdf/pe/v13n1/v13n1a08.pdf>Acesso em: 13 dez. 2015. 
Recebido em:15/08/2016 Aprovado em: 20/08/2016 